\title{
KONTRIBUSI BRAND IMAGE BINA NUSANTARA UNIVERSITY TERHADAP MINAT SEKTOR INDUSTRI ATAS ALUMNI
}

\author{
Tinjung Desy Nursanti ${ }^{1}$; Masruroh ${ }^{2}$; Cooky Tri Adhikara ${ }^{3}$ \\ 1,2,3 Jurusan Manajemen, Fakultas Ekonomi dan Bisnis, Universitas Bina Nusantara, \\ Jln. K.H. Syahdan No. 9, Palmerah, Jakarta Barat 11480 \\ tinjungdesy@yahoo.com
}

\begin{abstract}
Brand image is the existence of characteristic of a number of associations leading to unity of meaning, which ultimately determines general consumer reaction in providing assessments or responses to a brand. The marketing communication efforts by the company may be able to present a flexible technique in shaping consumer perceptions towards products and services offered to consumers and to help create image and attributes for users. From the eyes of the public as consumers, brand image is developed gradually, starting from the first appearance of the brand in the wider community, known, and perceived by the public. The industrial sector as users of academic products shall be more selective in their choices. One consideration to be taken into factor is that of an alumnus of a university with a trusted reputation. In this case, Binus University has an image as one of the leading private university in Jakarta. This study analyzes the brand image of Binus University for the industrial sector, related associations Binus University and how much is the spread of influence in order to get the picture of quality and popularity of Binus University in the minds of the industrial sectors.
\end{abstract}

Keywords: contribution, brand image, industry, alumni

\begin{abstract}
ABSTRAK
Brand image adalah adanya karakteristik sejumlah asosiasi yang menimbulkan kesatuan arti, yang pada akhirnya kesatuan arti tersebut menentukan reaksi konsumen secara terpadu dalam memberikan penilaian atau tanggapan terhadap suatu merek (brand). Adapun upaya komunikasi pemasaran yang dilakukan perusahaan dapat menyajikan teknik yang fleksibel dalam membentuk persepsi konsumen terhadap produk maupun jasa yang ditawarkan terhadap konsumen serta membantu menciptakan atribut dan image bagi para pengguna. Dari kaca mata masyarakat selaku konsumen, brand image muncul secara bertahap, dimulai dari kemunculan brand pertama kali di masyarakat luas, dikenal, dan dipersepsikan oleh masyarakat. Sektor industri sebagai pengguna produk akademis tentunya akan selektif dalam menentukan pilihan. Salah satu faktor pertimbangannya adalah alumni dari perguruan tinggi dengan reputasi terpercaya. Dalam hal ini, Binus University memiliki image sebagai salah satu perguruan tinggi swasta terkemuka di Jakarta. Penelitian ini menganalisis brand image Binus University bagi sektor industri, asosiasi yang terkait dengan Binus University dan seberapa besar pengaruhnya sehingga mendapatkan gambaran kualitas dan popularitas Binus University di benak sektor industri.
\end{abstract}

Kata kunci: kontribusi, brand image, industri, alumni 


\section{PENDAHULUAN}

Riuh globalisasi kian meningkat, kompetisi kian sengit, aktivitas perekonomian berlangsung semakin cepat. Hal demikian memberikan dampak terhadap berbagai perusahaan selaku pemain ekonomi untuk mampu beradaptasi. Perusahaan-perusahaan yang mampu bertahan adalah perusahaan yang mampu menyajikan produk sesuai dengan harapan konsumen atas dasar pergeseran yang mewarnai pola hidup masyarakat dewasa ini. Hal-hal di atas berdampak terhadap meluasnya peluang pemasaran produk maupun jasa. Secara umum produk dikategorikan ke dalam 3 bentuk, yaitu produk manufaktur seperti mainan, industri otomotif, sepatu, dan lain-lain. Bentuk kedua termasuk dalam kategori jasa keras seperti industri periklanan, leasing peralatan, maupun penyediaan perangkat lunak komputer. Adapun yang dapat dimasukkan ke dalam kategori ketiga adalah berbagai jasa lunak seperti restoran, hotel, rumah sakit termasuk institusi pendidikan (Ekelodo dan Sivakumar, 1998).

Salah satu indikator yang menunjukkan kemapanan posisi perusahaan di mata masyarakat adalah brand. Dirasakan pula peranan brand sangat besar bagi peningkatan kualitas produk yang disampaikan oleh produsen. Dari sisi konsumen, kesediaan mereka untuk mengonsumsi produk atau jasa yang ditawarkan oleh brand tertentu semakin meningkatkan manfaat brand bagi perusahaan yang mengeluarkannya. Konsep brand sudah dikenal masyarakat luas sebagai suatu simbol, nama, istilah, tanda atau apapun kombinasinya yang dikenal masyarakat yang melekat pada suatu produk maupun jasa. Kombinasi tersebut berfungsi untuk mengidentifikasi produk maupun jasa yang dihasilkan perusahaan. Identifikasi yang dimaksudkan ditujukan untuk membedakan produk perusahaan dengan produk pesaing (Keller, 1993).

Pada saat pertama kali didirikan, Bina Nusantara ditujukan sebagai salah satu sekolah tinggi yang bergerak di bidang ilmu komputer yang secara perlahan-lahan dikenal oleh masyarakat luas sebagai salah satu STMIK terkemuka di Jakarta. Pada tahap tersebut, institusi mulai mengembangkan apa yang disebut dengan brand building, yaitu dengan pemberian nama STMIK Bina Nusantara. Pemberian nama dimaksudkan untuk menunjukkan perbedaan antara sekolah tinggi yang lain. Dengan demikian, masyarakat mulai mengenal dan menyadari keberadaan sekolah tinggi ini. Pada tahap ini mulai muncul apa yang disebut dengan brand awareness, yaitu kesadaran masyarakat atas institusi pendidikan yang bergerak di bidang teknologi informatika dan komputer yang bernama Bina Nusantara.

Dalam rangka mendapatkan siswa sesuai dengan kapasitas maupun kompetensi yang dimiliki, tentu saja sekolah ini harus terus berupaya mengembangkan diri, kemudian sekolah tinggi ini mulai memperbanyak jurusan dan fakultas yang dimiliki dengan berganti nama menjadi Universitas Bina Nusantara. Dengan demikian, dapat dikatakan bahwa perusahaan yang dalam hal ini institusi pendidikan telah berupaya untuk menyampaikan paket lengkap atas bisnis pendidikan yang dijalankannya kepada para konsumennya. Dapat dikatakan Bina Nusantara telah memiliki brand identity. Termasuk di dalamnya adalah reputasi layanan yang ditawarkan, kualitas produk (dalam hal ini lulusan Bina Nusantara), fitur yang menjadi keunggulan Bina Nusantara, benefit, performa serta nilai.

Dari kaca mata masyarakat selaku konsumen, brand image muncul secara bertahap dimulai dari kemunculan brand pertama kali di masyarakat luas, dikenal dan dipersepsikan oleh masyarakat, di mana dalam hal ini Bina Nusantara memiliki image sebagai salah satu perguruan tinggi swasta terkemuka di Jakarta. Oleh karena itu, jelas bahwa Bina Nusantara selaku institusi pendidikan berupaya menyodorkan kelebihan apa yang dimilikinya dan menjadikannya sebagai identitas merek (brand identity), sedangkan citra merek (brand image) menunjukkan apa yang dipersepsikan oleh konsumen (Susanto, 2006). 
Dihadapkan kepada era pasar bebas yang mau tidak mau mempengaruhi eksistensi perguruan tinggi di Indonesia, selaku salah satu institusi pendidikan tinggi, Bina Nusantara harus terus menerus berupaya mengembangkan konsep maupun menampilkan image yang positif sebagai perguruan tinggi yang adaptif terhadap perubahan yang terjadi serta dapat memenuhi perkembangan dan tuntutan masyarakat. Bina Nusantara memiliki visi untuk mewujudkan perguruan tinggi kelas dunia (worldclass university), maka pada tahun 2008 sebagai salah satu upaya untuk menyesuaikan diri dengan pangsa pasar yang akan dihadapi, dilakukan penggantian nama menjadi Binus University. Diharapkan penggantian brand tersebut akan semakin menampilkan image positif yang sebaik-sebaiknya agar benar-benar menjadi image yang sesuai dengan potensi, kompetensi, kapasitas, dan berbagai sumber daya yang dimiliki. Oleh karena itu, kemampuan menampilkan image positif bahwa Binus University merupakan salah satu institusi pendidikan tinggi yang layak dipercaya, diyakini menjadi salah satu faktor pendukung utama keberhasilan Binus University untuk mampu bertahan dan melakukan pengembangan berbagai programnya. Sejumlah unsur masyarakat yang bertautan erat dengan dunia pendidikan tinggi, dalam hal menampilkan image kepada masyarakat, yaitu pemerintah, dunia industri, masyarakat secara umum, dan kalangan pers.

Sektor industri sebagai pengguna produk akademis tentunya akan selektif dalam menentukan pilihan. Salah satu faktor pertimbangannya adalah alumni dari perguruan tinggi dengan reputasi terpercaya. Tidak jarang pada kolom lowongan mereka langsung mencantumkan beberapa nama perguruan tinggi pilihan. Untuk menjadi perguruan tinggi seperti ini tidaklah mudah. Positioning sebuah perguruan tinggi di benak sektor industri terkait dengan Brand Management, yang sadar atau tidak telah diterapkan perguruan tinggi itu. Oleh karena itu, dari apa yang dipaparkan sebelumya, penelitian ini bertujuan untuk mengetahui beberapa hal yang terkait dengan brand image Binus University, brand identity Binus University, faktor penentu minat sektor industri serta ada tidaknya hubungan brand image terhadap minat sektor industri.

Adapun tujuan penelitian ini adalah untuk mengetahui bagaimana brand image Binus University bagi sektor industri, mengetahui brand identity yang dibangun oleh Binus University, dan mengetahui pengaruh brand image Binus University terhadap minat sektor industri atas alumni Binus University.

Dalam American Marketing Association seperti dikutip oleh Kotler (2006:256) dijelaskan sebagai berikut "brand as a name, term, sign, symbol, or design, or a combination of them, intended to identity of goods or services of one seller or group of sellers and to differentiate them from those of competitors". Merek didefinisikan sebagai sebuah nama, istilah, tanda, simbol atau desain atau kombinasi diantaranya, yang ditujukan untuk memberi identitas suatu produk dari penjual atau kelompok penjual dan untuk membedakan produk dari pesaing lainnya. Dengan demikian, merek mengandung janji perusahaan untuk secara konsisten memberikan ciri, manfaat, dan jasa tertentu kepada pembeli.

Nicolino (2004), menyatakan bahwa merek adalah entitas yang mudah dikenali dan menjanjikan nilai-nilai tertentu. Sebuah nama, logo, singkatan, desain, atau apa saja dapat dikatakan sebagai merek apabila memenuhi 4 hal berikut, yakni (1) Dapat dikenali (identifiable), dapat dengan mudah memisahkan satu barang yang serupa dengan yang lainnya melalui beberapa cara, biasanya berupa sepatah kata, warna, atau simbol (logo) yang dapat dilihat secara langsung; (2) Memiliki entitas, sesuatu yang mempunyai eksistensi yang khas atau berbeda; (3) Mengandung jani-janji tertentu (specific promises), suatu produk atau jasa membuat klaim mengenai apa yang dapat diberikannya; dan (4) Mengandung nilai-nilai, apapun yang didapatkan konsumen pasti merupakan sesuatu yang konsumen peduli hingga batas tertentu.

Di samping itu, merek dapat menjadi lebih dari sekedar jaminan kualitas karena dalam merek terkandung 6 pengertian (Kotler, 2003:418), yaitu (1) Atribut produk, meliputi kualitas, gengsi, nilai jual kembali, desain, dan sebagainya; (2) Manfaat, konsumen sebenarnya membeli produk, yang dibeli 
adalah manfaat dari produk, tidak hanya sekedar atribut produk saja. Atribut merek diperlukan untuk menterjemahkan manfaat fungsional ataupun manfaat emosional suatu produk; (3) Nilai, merek juga menyatakan sesuatu tentang nilai produsen. Nilai produsen ini ditentukan oleh nilai merek sebuah produk yang dihasilkan oleh produsen tersebut; (4) Budaya, merek mencerminkan budaya tertentu, misalnya Mercedes mencerminkan budaya Jerman yang terorganisir, konsisten, tingkat keseriusan tinggi, cermat, efisien, dan berkualitas tinggi; (5) Kepribadian, merek juga mencerminkan kepribadian tertentu. Seringkali produk merek tertentu menggunakan kepribadian orang terkenal untuk mendongkrak atau menopang merek produknya; dan (6) Pemakai, merek suatu produk menunjukkan tipe konsumen yang membeli atau menggunakannya.

White (2006) menjelaskan konsep brand identity sebagai paket lengkap bisnis bagi konsumennya, yang meliputi reputasi layanan yang ditawarkan perusahaan, kualitas produk, fitur, benefit, performa, dan nilai. Dapat dikatakan bahwa penjumlahan seluruh variabel di atas menciptakan apa yang dikenal dengan brand identity. Sedangkan pengertian brand image mengacu kepada persepsi pasar terhadap brand identity yang dapat atau tidak dapat menyatu dengan brand identity yang dibangun. Dalam penelitian yang dilakukannya, Keller (1993) menyatakan bahwa perpaduan yang menyebabkan terjadinya brand image adalah adanya karakteristik sejumlah asosiasi yang menimbulkan kesatuan arti, yang pada akhirnya kesatuan arti tersebut menentukan reaksi konsumen secara terpadu dalam memberikan penilaian atau tanggapan terhadap suatu merek (brand). Asosiasi merek (brand association) dengan demikian akan membentuk brand image. Melalui asosiasi merek, segala kesan akan muncul di benak seseorang terkait dengan ingatannya mengenai suatu merek (Durianto et al., 2004:69).

Umumnya asosiasi merek yang dapat membentuk brand image menjadi pijakan konsumen dalam keputusan pembelian dan loyalitasnya pada merek tersebut. Pada praktiknya, banyak didapati kemungkinan asosiasi dan variasi dari brand association yang dapat memberikan nilai bagi suatu merek, dipandang dari sisi perusahaan maupun dari sisi pengguna. Berbagai fungsi dari asosiasi tersebut adalah (1) Membantu proses penyusunan informasi (retrieve information), (2) Memberikan landasan yang penting bagi upaya pembedaan suatu merek dari merek lain (differentiate), (3) Brand association membangkitkan berbagai atribut produk atau manfaat bagi konsumen (customer benefit) yang dapat memberikan alasan spesifik bagi konsumen untuk membeli dan menggunakan merek tersebut (reason to buy), (4) Beberapa asosiasi mampu merangsang suatu perasaan positif atas dasar pengalaman mereka sebelumnya serta mengubah pengalaman tersebut menjadi sesuatu yang lain daripada yang lain (create positive attitude/ feelings), dan (5) Suatu asosiasi dapat menghasilkan landasan bagi suatu perluasan dengan menciptakan rasa kesesuaian (sense of fit in) antara merek dengan sebuah produk baru, atau menghadirkan alasan untuk membeli produk perluasan tersebut (basis for extension).

Adapun upaya komunikasi pemasaran yang dilakukan perusahaan dapat menyajikan teknik yang fleksibel dalam membentuk persepsi konsumen terhadap produk maupun jasa yang ditawarkan terhadap konsumen serta membantu menciptakan atribut dan image bagi para pengguna. Penelitian lebih lanjut yang dilakukan oleh Hansen dan Christensen (2007) mengidentifikasi dengan cara bagaimana konsumen melakukan evaluasi terhadap corporate brand. Hasil temuan keduanya menunjukkan bahwa hal tersebut memudahkan perusahaan mengevaluasi dan membuat strategi untuk merencanakan image seperti apa yang tepat diaplikasikan terhadap brand perusahaan.

\section{METODE PENELITIAN}

Terkait bidang keilmuan yang sesuai dengan maksud dan tujuan penelitian, pada dasarnya pendekatan yang digunakan dalam penelitian ini adalah ilmu manajemen pemasaran, khususnya yang 
terkait dengan brand image. Penelitian dilakukan terhadap sektor industri atas penilaiannya terhadap brand image dan minat mereka menjadikan alumni Binus University sebagai karyawannya.

Tabel 1 Desain Penelitian

\begin{tabular}{ccll}
\hline $\begin{array}{c}\text { Tujuan } \\
\text { Penelitian }\end{array}$ & Jenis Penelitian & \multicolumn{1}{c}{ Unit Analisis } & Time Horizon \\
\hline T1 & Deskriptif & $\begin{array}{l}\text { Organisasi/ perusahaan selaku pengguna } \\
\text { alumni (user) }\end{array}$ & One shoot-cross sectional \\
T2 & Deskriptif & Sektor industry & One shoot-cross sectional \\
T3 & Deskriptif & Sektor industry & One shoot-cross sectional \\
\hline & & Sumber: Hasil Penelitian Penulis (2008)
\end{tabular}

\section{Keterangan:}

T1 : Mengetahui karakteristik responden

T2 : Mengetahui seberapa besar kontribusi brand image terhadap minat sektor industri atas alumni Binus University

T3 : Mengetahui ada tidaknya hubungan dan pengaruh brand image terhadap minat sektor industri atas alumni

Tabel 2 Jenis Data dan Sumber Data

\begin{tabular}{ll}
\hline \multicolumn{1}{c}{ Jenis Data } & \multicolumn{1}{c}{ Sumber Data } \\
\hline Jumlah alumni Binus University & Data sekunder dari Binus Career \\
Brand identity & Data primer dari kuesioner sektor industri \\
Minat sektor industri & Data primer dari kuisioner sektor industri, melalui \\
& Binus Career, Job-Expo, distribusi langsung ke sector \\
& industri \\
& Data sekunder dari literatur \\
\hline
\end{tabular}

Sumber: Hasil Penelitian Penulis (2008)

Mengingat jumlah alumni Binus University yang besar dan tersebar pada sejumlah perusahaan, perlu dilakukan pencarian informasi dari Binus Career untuk mengetahui secara pasti jumlah alumni Binus University. Informasi yang terkumpul dapat digunakan untuk mengetahui sektorsektor industri yang paling banyak dimasuki oleh alumni Binus University. Setelah itu, pengumpulan data dengan menggunakan kuesioner yang akan disebarluaskan kepada sektor industri direncanakan akan dilaksanakan pada saat job-expo di lingkungan kampus Binus University yang akan berlangsung pada bulan Juli.

Untuk memperoleh data yang dibutuhkan dalam penelitian ini, digunakan 3 teknik pengumpulan data, yaitu (1) Observasi dilakukan sebagai tahapan awal penelitian dan saat penelitian berlangsung atas semua data yang dibutuhkan; (2) Wawancara dengan pihak yang terkait dengan topik penelitian ini, yaitu bagian marketing, humas dan eksekutif Binus University; (3) Kuesioner kepada sektor industri. 


\section{Metode Analisis}

Dalam penelitian ini, dilakukan beberapa pengujian. Pertanyaan pertama dapat diteliti dengan cara melakukan analisis deskriptif kuantitatif, dengan melihat distribusi frekuensi berdasarkan data yang tersedia serta melalui data primer yang dikumpulkan dengan cara menyebarkan kuesioner kepada responden, yaitu masyarakat umum, yang dalam hal ini diwakili oleh sektor industri. Tujuan yang ingin dicapai adalah untuk mengetahui karakteristik responden seperti jenis bidang usaha, lama perusahaan beroperasi maupun jumlah karyawan dan perkiraan kebutuhan karyawan. Pertanyaan kedua dapat diteliti dengan melakukan analisis deskriptif kuantitatif dengan uji Cochran atas variabelvariabel yang ada. Pertanyaan ketiga dapat diuji melalui korelasi mengenai ada tidaknya hubungan antara brand image dengan minat sektor industri terhadap alumni Binus University (Cooper dan Emory, 1999).

Tabel 3 Metode Penelitian

\begin{tabular}{cll}
\hline Tujuan Penelitian & \multicolumn{1}{c}{ Metode } & \multicolumn{1}{c}{ Alat Analisis } \\
\hline T1 & Deskriptif Survai & Analisis deskriptif - distribusi frekuensi \\
T2 & Deskriptif Survai & Analisis deskriptif - uji Cochran \\
T3 & Deskriptif Survai & Analisis korelasional - regresi korelasi \\
\hline
\end{tabular}

\section{HASIL DAN PEMBAHASAN}

Faktor-faktor pertimbangan pemilihan calon tenaga kerja adalah sebagai berikut.

Q1 = Reputasi dan nama besar perguruan tinggi menjadi pertimbangan dalam merekrut calon tenaga kerja

Q2 = Rekomendasi dari sejumlah pihak menjadi pertimbangan penting

Q3 = Kinerja tenaga kerja yang sedang bekerja pada user saat ini yang merupakan alumni dari perguruan tinggi yang bersangkutan

$\mathrm{Q} 4=$ Penilaian objektif atas kualitas alumni suatu perguruan tinggi

Q5 = Keragaman bidang kekhususan yang dimiliki perguruan tinggi

Q6 = Kompetensi bidang keahlian tertentu dalam suatu perguruan tinggi

Q7 = Kemampuan alumni dalam bidang kekhususan/keahlian

Q8 = Prestasi mahasiswa melalui berbagai ajang kompetisi

Q9 = Soft-Skill calon tenaga kerja

$\mathrm{Q} 10=$ Banyaknya alumni perguruan tinggi ybs yang terserap berbagai user

Q11 = Prestasi akademik alumni

Q12 = Kesesuaian syarat kualifikasi calon tenaga kerja dengan yang ditetapkan user

Q13 = Kesesuaian visi calon tenaga kerja dengan visi user

Q14 = Orientasi kerja calon tenaga kerja 
Tabel 4 Validasi Butir Pertanyaan

\begin{tabular}{cccl}
\hline Pertanyaan & r hitung & r tabel & Keterangan \\
\hline Q1 & 0,126 & 0,241 & Tidak valid \\
Q2 & 0,429 & 0,241 & Valid \\
Q3 & 0,387 & 0,241 & Valid \\
Q4 & 0,451 & 0,241 & Valid \\
Q5 & 0,607 & 0,241 & Valid \\
Q6 & 0,436 & 0,241 & Valid \\
Q7 & 0,212 & 0,241 & Tidak Valid \\
Q8 & 0,603 & 0,241 & Valid \\
Q9 & 0,495 & 0,241 & Valid \\
Q10 & 0,290 & 0,241 & Valid \\
Q11 & 0,132 & 0,241 & Tidak Valid \\
Q12 & 0,328 & 0,241 & Valid \\
Q13 & 0,340 & 0,241 & Valid \\
Q14 & 0,305 & 0,241 & Valid \\
\hline
\end{tabular}

Sumber: Pengolahan data (2008)

Berdasarkan Tabel 4, validasi butir pertanyaan untuk faktor-faktor pertimbangan pemilihan calon tenaga kerja terdapat 3 butir pertanyaan yang tidak valid, yaitu Q1, Q7, dan Q11 sehingga dikeluarkan pada analisis selanjutnya.

Tabel 5 Uji Reliabilitas Faktor-Faktor Pertimbangan

\begin{tabular}{ccc}
\hline $\begin{array}{c}\text { Cronbach's } \\
\text { Alpha }\end{array}$ & $\begin{array}{c}\text { Cronbach's Alpha Based on } \\
\text { Standardized Items }\end{array}$ & $\begin{array}{c}\text { N of } \\
\text { Items }\end{array}$ \\
\hline, 666 &, 650 & 14 \\
\hline
\end{tabular}

Analisis yang digunakan dalam penelitian ini menggunakan metode statistik deskriptif, uji Cochran, dan analisis regresi linier sederhana. Kelemahan analisis data menurut Tjiptono dan Santoso (2004:119), Descriptive Statistics Frequencies ini dapat digunakan untuk menampilkan dan mendeskripsikan (menggambarkan) data yang terdiri atas satu variabel saja. Menu frequencies menampilkan setiap data yang ada dan bukan dalam range (interval data). Sedangkan uji Cochran mempunyai kelemahan, yaitu tidak dapat menentukan besaran dari asosiasi yang terbentuk (brand image). Uji Cochran tidak dapat menentukan asosiasi mana yang lebih besar di antara asosiasi-asosiasi yang membentuk brand image suatu produk.

\section{Hasil Penelitian}

\section{Profil Responden}

Merupakan informasi pendukung yang berkaitan dengan brand image alumni Binus University antara lain sebagai berikut. Pertama, jenis industri. Berdasarkan hasil jawaban 100 responden pada saat ini alumni Binus bekerja pada jenis industri, dapat ditunjukkan dengan Bar Chart di bawah ini (Gambar 1). 


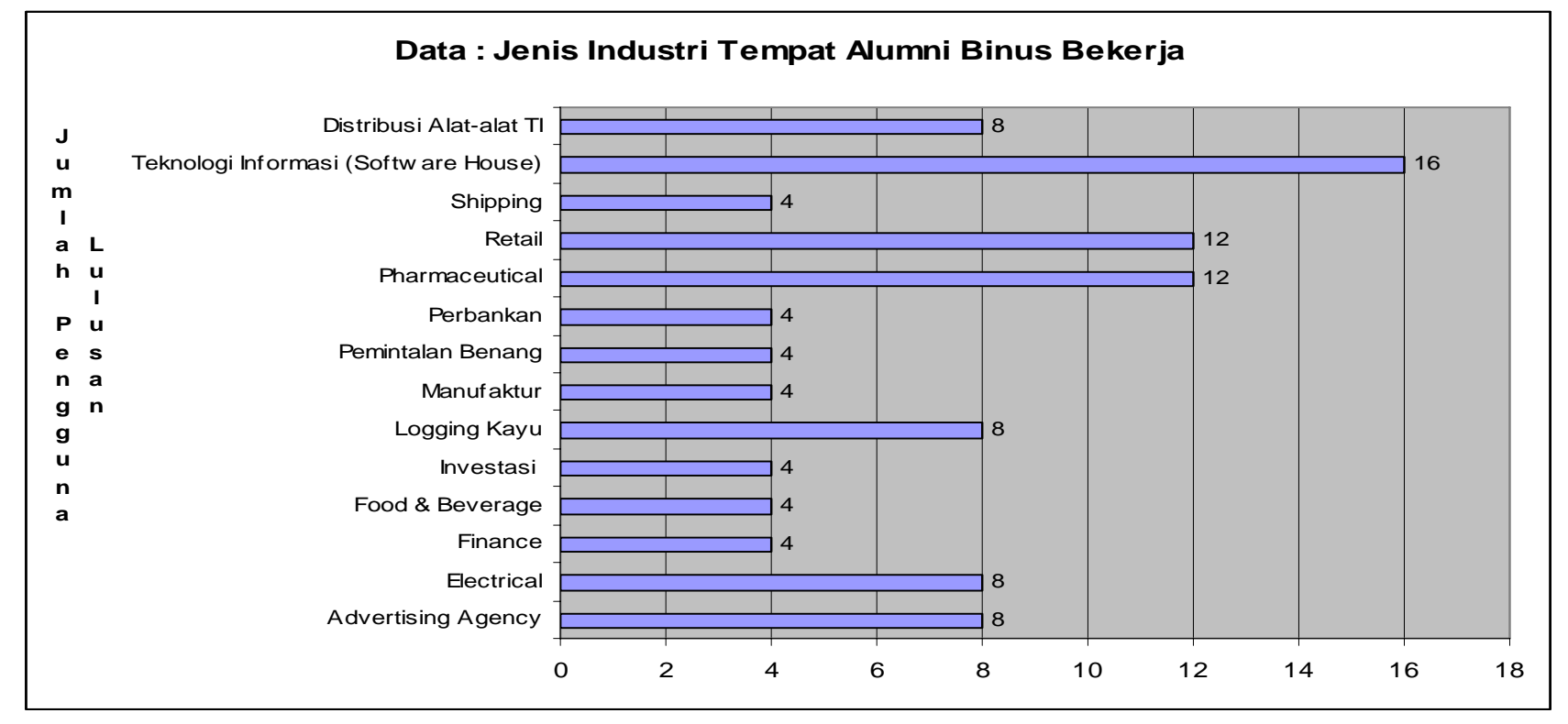

Gambar 1 Jenis Industri Tempat Alumni Binus Bekerja

Kedua, jumlah tenaga kerja saat ini. Aset yang memberikan kontribusi terbesar bagi perusahaan adalah tenaga kerja. Oleh karena itu, diperlukan data jumlah tenaga kerja yang terkini dengan informasi berikut (Tabel 6).

Tabel 6 Jumlah Tenaga Kerja Saat Ini

\begin{tabular}{|c|c|c|c|c|c|}
\hline Jenis Industri & $<20$ Orang & $\begin{array}{c}20 \text { s.d. } 40 \\
\text { Orang }\end{array}$ & $\begin{array}{c}40 \text { s.d } 60 \\
\text { Orang }\end{array}$ & $>60$ Orang & Grand Total \\
\hline Advertising Agency & & & & 8 & 8 \\
\hline Distribusi alat-alat TI & 4 & & & 4 & 8 \\
\hline Electrical & & & & 8 & 8 \\
\hline Finance & & & & 4 & 4 \\
\hline Food \& Beverage & & & & 4 & 4 \\
\hline Investasi & & & 4 & 0 & 4 \\
\hline Logging Kayu & & & & 8 & 8 \\
\hline Manufaktur & & 4 & & 0 & 4 \\
\hline Pemintalan Benang & & & & 4 & 4 \\
\hline Perbankan & & & & 4 & 4 \\
\hline Pharmaceutical & & & & 12 & 12 \\
\hline Retail & & & & 12 & 12 \\
\hline Shipping & & & & 4 & 4 \\
\hline Teknologi Informasi & & 4 & & 12 & 16 \\
\hline Grand Total & 4 & 8 & 4 & 84 & 100 \\
\hline Persentase & $4,00 \%$ & $8,00 \%$ & $4,00 \%$ & $84,00 \%$ & $100,00 \%$ \\
\hline
\end{tabular}

Sumber: Hasil Penelitian Penulis (2008)

Ketiga, lama perusahaan beroperasi. Operasional perusahaan yang berjalan sampai dengan saat ini untuk masing-masing jenis industri yang terkait dengan tempat bekerja alumni Binus, dapat ditunjukkan oleh tabel di bawah ini (Tabel 7). 
Tabel 7 Lama Perusahaan Beroperasi

\begin{tabular}{|c|c|c|c|c|c|}
\hline Jenis Industri & $<1$ Tahun & 1 s.d. 5 Tahun & 5 s.d. 10 Tahun & $>10$ Tahun & Grand Total \\
\hline Advertising Agency & & & & 8 & 8 \\
\hline Distribusi alat-alat TI & & 4 & & 4 & 8 \\
\hline Electrical & & & & 8 & 8 \\
\hline Finance & & & & 4 & 4 \\
\hline Food \& Beverage & & & & 4 & 4 \\
\hline Investasi & & & 4 & & 4 \\
\hline Logging Kayu & & & & 8 & 8 \\
\hline Manufaktur & & & & 4 & 4 \\
\hline Pemintalan Benang & & & & 4 & 4 \\
\hline Perbankan & & & & 4 & 4 \\
\hline Pharmaceutical & & & & 12 & 12 \\
\hline Retail & & 4 & & 8 & 12 \\
\hline Shipping & & & & 4 & 4 \\
\hline Teknologi Informasi & & 4 & 4 & 8 & 16 \\
\hline Grand Total & $\mathbf{0}$ & 12 & 8 & 80 & 100 \\
\hline Persentase & $0,00 \%$ & $12,00 \%$ & $8,00 \%$ & $80,00 \%$ & $100,00 \%$ \\
\hline
\end{tabular}

Sumber: Hasil Penelitian Penulis (2008)

Keempat, perkiraan kebutuhan jumlah tenaga kerja per tahun. Turn Over karyawan dan penambahan divisi baru mengakibatkan pengguna lulusan secara cepat mengisi karyawan yang baru sehingga perkiraan akan kebutuhan tenaga kerja menjadi poin yang penting agar perusahaan tetap berjalan dengan baik (Tabel 8).

Tabel 8 Perkiraan Kebutuhan Jumlah Tenaga Kerja per Tahun

\begin{tabular}{|c|c|c|c|c|c|}
\hline Jenis Industri & $\begin{array}{c}<\mathbf{1 0} \\
\text { Orang }\end{array}$ & 10 s.d. 20 Orang & 20 s.d. 30 Orang & > 30 Orang & $\begin{array}{c}\text { Grand } \\
\text { Total }\end{array}$ \\
\hline Advertising Agency & & & 4 & 4 & 8 \\
\hline Distribusi alat-alat TI & 4 & & & 4 & 8 \\
\hline Electrical & & 4 & & 4 & 8 \\
\hline Finance & & & & 4 & 4 \\
\hline Food \& Beverage & & & & 4 & 4 \\
\hline Investasi & & & 4 & & 4 \\
\hline Logging Kayu & & & & 8 & 8 \\
\hline Manufaktur & & & & 4 & 4 \\
\hline Pemintalan Benang & & & & 4 & 4 \\
\hline Perbankan & & & 4 & & 4 \\
\hline Pharmaceutical & & & & 12 & 12 \\
\hline Retail & 4 & 4 & & 4 & 12 \\
\hline Shipping & & & & 4 & 4 \\
\hline Teknologi Informasi & & 8 & & 8 & 16 \\
\hline Grand Total & 8 & 16 & 12 & 64 & 100 \\
\hline Persentase & $8,00 \%$ & $16,00 \%$ & $12,00 \%$ & $64,00 \%$ & $100,00 \%$ \\
\hline
\end{tabular}

Sumber: Hasil Penelitian Penulis (2008) 


\section{Analisis Brand Image Binus University}

Brand image adalah adanya karakteristik sejumlah asosiasi yang menimbulkan kesatuan arti, yang pada akhirnya kesatuan arti tersebut menentukan reaksi konsumen secara terpadu dalam memberikan penilaian atau tanggapan terhadap suatu merek (brand). Adapun upaya komunikasi pemasaran yang dilakukan perusahaan dapat menyajikan teknik yang fleksibel, dalam membentuk persepsi konsumen terhadap produk maupun jasa yang ditawarkan terhadap konsumen serta membantu menciptakan atribut dan image bagi para pengguna. Berikut tanggapan pengguna lulusan terhadap brand image Binus University dapat diuraikan dengan menggunakan pengujian asosiasi dengan metode Cochran (Tabel 9).

Tabel 9 Penilaian Responden akan Brand Image Binus University

\begin{tabular}{clcc}
\hline Kode & \multicolumn{1}{c}{ Asosiasi } & Ya & \% Ya \\
\hline Q1 & Komputer & 100 & $100 \%$ \\
Q2 & Universitas swasta terkenal & 88 & $88 \%$ \\
Q3 & Universitas swasta pertama di indonesia yang memiliki ISO & 52 & $52 \%$ \\
Q4 & Universitas swasta yang menjadi panutan/benchmark & 40 & $40 \%$ \\
Q5 & Universitas swasta yang bermutu dan inovatif & 88 & $88 \%$ \\
Q6 & Teknologi informasi up-to-date & 92 & $92 \%$ \\
Q7 & Fasilitas lengkap dan modern & 80 & $80 \%$ \\
Q8 & Proses pembelajaran dengan metode e-learning & 60 & $60 \%$ \\
Q9 & Alumni yang terampil dan andal & 88 & $88 \%$ \\
Q10 & Alumni mudah dan cepat terserap di dunia kerja & 92 & $92 \%$ \\
Q11 & Alumni yang dinamis dan profesional & 88 & $88 \%$ \\
Q12 & Orientasi dan etos kerja alumni bagus & 68 & $68 \%$ \\
\hline
\end{tabular}

Sumber: Hasil Penelitian Penulis (2008)

Selanjutnya, dilakukan uji Cochran untuk mengetahui asosiasi-asosiasi mana yang membentuk brand image dari Binus. Pengujian atribut-atribut tersebut dilakukan secara bertahap. Hipotesisnya adalah sebagai berikut.

$\mathrm{H}_{0}=$ Kemungkinan jawaban "ya" adalah sama untuk semua asosiasi

$\mathrm{H}_{1}=$ Kemungkinan jawaban "ya" adalah berbeda untuk semua asosiasi

Dasar pengambilan keputusan, yakni:

Signifikansi $<0,05 \rightarrow$ Tolak $\mathrm{H}_{0}$

Signifikansi $\geq 0,05 \rightarrow$ Terima $\mathrm{H}_{0}$

Tabel 10 Ringkasan Pengujian Asosiasi Brand Image Binus University

\begin{tabular}{|c|c|c|c|c|}
\hline Iterasi & Penggunaan Atribut Asosiasi & Asymp Signifikansi & Alpha & Keterangan \\
\hline 1 & Semua Asosiasi & 0,000 & 0,050 & $\mathrm{H}_{0}$ Ditolak \\
\hline 2 & Q1,Q2,Q3,Q5,Q6,Q7,Q8,Q9,Q10,Q11,Q12 & 0,000 & 0,050 & $\mathrm{H}_{0}$ Ditolak \\
\hline 3 & Q1,Q2,Q5,Q6,Q7,Q8,Q9,Q10,Q11,Q12 & 0,000 & 0,050 & $\mathrm{H}_{0}$ Ditolak \\
\hline 4 & $\mathrm{Q} 1, \mathrm{Q} 2, \mathrm{Q} 5, \mathrm{Q} 6, \mathrm{Q} 7, \mathrm{Q} 9, \mathrm{Q} 10, \mathrm{Q} 11, \mathrm{Q} 12$ & 0,000 & 0,050 & $\mathrm{H}_{0}$ Ditolak \\
\hline 5 & $\mathrm{Q} 1, \mathrm{Q} 2, \mathrm{Q} 5, \mathrm{Q} 6, \mathrm{Q} 7, \mathrm{Q} 9, \mathrm{Q} 10, \mathrm{Q} 11$ & 0,000 & 0,050 & $\mathrm{H}_{0}$ Ditolak \\
\hline 6 & $\mathrm{Q} 1, \mathrm{Q} 2, \mathrm{Q} 5, \mathrm{Q} 6, \mathrm{Q} 9, \mathrm{Q} 10, \mathrm{Q} 11$ & 0,010 & 0,050 & $\mathrm{H}_{0}$ Ditolak \\
\hline 7 & Q1,Q5,Q6,Q9,Q10,Q11 & 0,005 & 0,050 & $\mathrm{H}_{0}$ Ditolak \\
\hline 8 & Q1,Q6,Q9,Q10,Q11 & 0,005 & 0,050 & $\mathrm{H}_{0}$ Ditolak \\
\hline 9 & Q1,Q6,Q10,Q11 & 0,004 & 0,050 & $\mathrm{H}_{0}$ Ditolak \\
\hline 10 & Q1,Q6,Q10 & 0,018 & 0,050 & $\mathrm{H}_{0}$ Ditolak \\
\hline 11 & Q1,Q10 & 0,051 & $\mathbf{0 , 0 5 0}$ & $\mathrm{H}_{0}$ Diterima \\
\hline
\end{tabular}

Sumber: Pengolahan Data (2008)

Catatan: Perhitungan Asymp Signifikansi dengan menggunakan SPSS V. 13. 
Setelah melalui pengujian hingga iterasi yang ke 11, maka nilai signifikansinya di atas 0,05 sehingga $\mathrm{H}_{0}$ diterima. Dengan demikian, atribut-atribut yang membentuk asosiasi brand image yang sangat kuat, yaitu komputer (Q1) dan alumni mudah dan cepat terserap di dunia kerja (Q10).

Hasil pengolahan data di atas pada dasarnya mewakili kenyataan yang dapat ditemui pada Binus University seperti kecanggihan teknologi. Hal ini dapat dilihat dari pemenuhan berbagai kebutuhan berbasis teknologi yang selalu update seperti misalnya pemanfaatan internet sebagai salah satu sumber informasi untuk memperoleh ilmu, baik bagi mahasiswa maupun para staf pengajarnya, penerapan sistem perkuliahan multi channel learning, yaitu penggunaan jaringan internet secara terpadu bagi civitas akademika Binus University untuk saling berbagi materi perkuliahan sehari-hari, dilengkapi dengan tugas-tugas yang harus diselesaikan dan dikumpulkan serta dinilai secara online. Selain itu, dengan brand yang sudah dikenal oleh masyarakat, berbagai instansi selaku user cenderung membuka peluang sebesar-besarnya bagi para alumni Binus University untuk memperoleh pekerjaan.

\section{Pengaruh Image Alumni Binus University terhadap Faktor-faktor Pertimbangan Calon Tenaga Kerja}

Untuk mengetahui adanya pengaruh atau tidak yang signifikan dari variabel image alumni Binus University (X) terhadap faktor-faktor pertimbangan calon tenaga kerja (Y), dapat menggunakan metode analisis regresi dan korelasi sederhana. Berikut hasil perhitungan dengan menggunakan program SPSS V. 13 (Tabel 11). Pertama, analisis korelasi. Hubungan 2 variabel dapat ditunjukkan dengan nilai koefisien korelasinya sebesar 0,629 dan signifikan dikarenakan Sig (1-tailed) bernilai < 0,05 sehingga ada hubungan yang positif dan cukup kuat dari kedua variabel tersebut.

Tabel 11 Perhitungan Koefisien Korelasi

\begin{tabular}{|c|c|c|c|}
\hline \multicolumn{4}{|c|}{ Correlations } \\
\hline & & $\begin{array}{c}\mathrm{Y}= \\
\text { Faktor-faktor } \\
\text { Pertimbangan } \\
\text { Pemilihan } \\
\text { Calon Tenaga } \\
\text { Kerja }\end{array}$ & $\begin{array}{c}X=\text { Image } \\
\text { Alumni Binus }\end{array}$ \\
\hline \multirow[t]{2}{*}{ Pearson Correlation } & $\begin{array}{l}\text { Y = Faktor-faktor } \\
\text { Pertimbangan Pemilihan } \\
\text { Calon Tenaga Kerja }\end{array}$ & 1,000 & ,629 \\
\hline & $X=$ Image Alumni Binus & 629 & 1,000 \\
\hline \multirow[t]{2}{*}{ Sig. (1-tailed) } & $\begin{array}{l}\text { Y = Faktor-faktor } \\
\text { Pertimbangan Pemilihan } \\
\text { Calon Tenaga Kerja }\end{array}$ & & ,000 \\
\hline & $X=$ Image Alumni Binus & ,000 & \\
\hline \multirow[t]{2}{*}{$\mathrm{N}$} & $\begin{array}{l}\text { Y = Faktor-faktor } \\
\text { Pertimbangan Pemilihan } \\
\text { Calon Tenaga Kerja }\end{array}$ & 100 & 100 \\
\hline & $X=$ Image Alumni Binus & 100 & 100 \\
\hline
\end{tabular}

Sumber: Pengolahan data dengan menggunakan program SPSS V. 13 
Tabel 12 Perhitungan $r$ dan $\mathrm{r}^{2}$

Model Summary

\begin{tabular}{|l|r|r|r|r|}
\hline Model & R & R Square & $\begin{array}{c}\text { Adjusted } \\
\text { R Square }\end{array}$ & $\begin{array}{r}\text { Std. Error of } \\
\text { the Estimate }\end{array}$ \\
\hline 1 &, $629^{\mathrm{a}}$ &, 396 &, 389 &, 169799 \\
\hline
\end{tabular}

a. Predictors: (Constant), $\mathrm{X}=$ Image Alumni Binus

Sumber: Pengolahan data dengan menggunakan program SPSS V. 13

Koefisien determinasi dapat ditunjukkan pada nilai $R$ Square sebesar 0,389 . Nilai tersebut dapat diartikan bahwa pengaruh brand image alumni terhadap faktor-faktor pertimbangan calon tenaga kerja sebesar $39,60 \%$, sedangkan sisanya sebesar $60,40 \%$ dipengaruhi oleh variabel selain brand image alumni.

Kedua, analisis regresi. Pada saat menggunakan metode analisis regresi, diperlukan persyaratan Tabel Anova untuk mengetahui apakah persamaan regresinya signifikan. Dari tabulasi di bawah diketahui nilai Sig $<0,05$. Dengan demikian, persamaan regresi yang digunakan dapat mewakili pengaruh 2 variabel yang dianalisis.

Tabel 13 Anova

ANOVA

\begin{tabular}{|c|c|c|c|c|c|c|}
\hline \multicolumn{2}{|c|}{ Model } & $\begin{array}{c}\text { Sum of } \\
\text { Squares }\end{array}$ & $\mathrm{df}$ & Mean Square & $F$ & Sig. \\
\hline \multirow[t]{3}{*}{1} & Regression & 1,849 & 1 & 1,849 & 64,141 &, $000^{a}$ \\
\hline & Residual & 2,826 & 98 & ,029 & & \\
\hline & Total & 4,675 & 99 & & & \\
\hline
\end{tabular}

a. Predictors: (Constant), $X=$ Image Alumni Binus

b. Dependent Variable: $Y=$ Faktor-faktor Pertimbangan Pemilihan Calon Tenaga Kerja

Persamaan Regresi Liner sederhana dapat ditunjukkan oleh tabel di bawah ini:

Tabel 14 Perhitungan Koefisien Persamaan Regresi Linier Sederhana

Coefficients

\begin{tabular}{|ll|r|r|r|r|r|}
\hline \multirow{2}{*}{ Model } & \multicolumn{2}{|c|}{$\begin{array}{c}\text { Unstandardized } \\
\text { Coefficients }\end{array}$} & $\begin{array}{c}\text { Standardized } \\
\text { Coefficients }\end{array}$ & & \\
\cline { 2 - 7 } & \multicolumn{1}{|c|}{$\mathrm{B}$} & Std. Error & Beta & $\mathrm{t}$ & Sig. \\
\hline & (Constant) & 1,938 &, 238 & 8,131 &, 000 \\
& X = Image Alumni Binu &, 504 &, 063 &, 629 & 8,009 &, 000 \\
\hline
\end{tabular}

a. Dependent Variable: $Y=$ Faktor-faktor Pertimbangan Pemilihan Calon Tenaga Kerja

Pengaruh image alumni Binus University $(\mathrm{X})$ terhadap faktor-faktor pertimbangan pemilihan calon tenaga kerja $(\mathrm{Y})$ dapat ditunjukkan oleh persamaan regresi yang dibentuk oleh konstanta dan koefisien persamaan regresinya:

$$
\mathrm{Y}=1,938+0,504 \mathrm{X}
$$


Persamaan regresi yang terbentuk dari hasil perhitungan dapat diinterpretasikan bahwa semakin meningkatnya image alumni Binus University sebesar 1 satuan akan memberikan kontribusi sebesar 0,504 poin pada faktor-faktor pertimbangan pemilihan calon tenaga kerja. Dengan kata lain, dapat dijelaskan bahwa peningkatan image alumni Binus akan berbanding lurus dengan faktor-faktor pertimbangan pemilihan calon tenaga kerjanya.

\section{SIMPULAN}

Setelah melalui prosedur penelitian, pengolahan data dan analisis data sebagaimana yang telah dijabarkan sebelumnya, maka simpulan yang dapat ditarik dari penelitian ini adalah sebagai berikut (1) Berdasarkan analisis deskriptif mengenai jenis perusahaan dan lama berdirinya perusahaan, diketahui bahwa sebagian besar alumni Binus University terjun ke bidang pekerjaan yang berhubungan dengan teknologi informasi; (2) Dari pengujian Cochran yang dilakukan terhadap berbagai asosiasi yang melekat dari Binus University, diperoleh hasil bahwa hanya diperoleh 2 asosiasi dari 11. Dengan demikian, dapat disimpulkan bahwa Binus University sebagai salah satu perguruan tinggi terkemuka yang memiliki berbagai disiplin ilmu memang masih dikenal masyarakat sebagai institusi pendidikan berbasis teknologi. Tampaknya hasil ini selaras dengan strategi Binus University dengan sistem pengajarannya yang berbasiskan TI. Strategi yang tepat disertai kerja keras selama bertahun-tahun membuahkan hasil positif terbentuknya citra tertentu terhadap brand BINUS. Kini, Universitas Bina Nusantara telah berevolusi menjadi Binus University sehingga telaah aplikasi strategi terhadap Universitas Bina Nusantara perlu dipertimbangkan apakah perlu menerapkan strategi yang berbeda dengan Binus University.

Saran yang diberikan, yaitu (1) Perlu mempertahankan strategi yang dapat menghasilkan asosiasi yang dapat membentuk brand image yang sangat kuat yaitu "komputer" dan "alumni mudah dan cepat terserap pada dunia kerja". Ini adalah keunggulan kompetitif bagi Binus University; dan (2) Seiring perubahan nama Universitas Bina Nusantara menjadi Binus University, maka diperlukan strategi tertentu sehingga akan diperoleh asosiasi "berstandar internasional" dan "kampus terbaik". Penelitian ini masih memiliki keterbatasan seperti minimnya jumlah responden yang berhasil digali melalui penyebaran kuesioner yang dilakukan meskipun sudah memenuhi standar minimal yang diperlukan untuk dianalisis. Kesulitan yang dihadapi antara lain adalah tidak semua perusahaan bersedia mengisi responden yang dibagikan. Apabila diperoleh responden lebih besar barangkali hasil analisis akan berbeda dari apa yang ditemukan saat ini. Ke depannya bila memungkinkan masih ada celah untuk melakukan penelitian serupa, akan tetapi ditujukan ke beberapa perguruan tinggi yang berbeda untuk mengetahui perguruan tinggi yang manakah yang telah melakukan brand building-nya dengan baik. 


\section{DAFTAR PUSTAKA}

Durianto, Darmadi, Sugiarto, dan Sitinjak. (2004). Strategi menaklukkan pasar melalui riset ekuitas dan perilaku merek, Jakarta: Gramedia Pustaka Utama.

Ekeledo, I., and Sivakumar, K. F. (1998). Foreign market entry mode choice of service firms: A contingency perspective. Academy of Marketing Science Journal, Greenvale: 26(4), 274-293.

Hansen, F., and Christensen, L.B. (2007). Dimensions in consumer evaluation of corporate brands and the role of emotional response strength (Ners). Innovative Marketing, 3(3), 19-29.

Keller, K.L. (1993). Conceptualizing, measuring and managing customer-based brand equity. Journal of Marketing, 57, January, 1-22.

Kotler, P., and Keller, K.L. (2006). Marketing management, $12^{\text {th }}$ ed., Upper Saddle River, New Jersey: Pearson Education, Inc.

Kotler, P., (2003). Marketing management $11^{\text {th }}$ Ed. Prentice Hall.

Santoso, S. dan Tjiptone, F. (2004). Riset pemasaran: konsep dan Aplikasi dengan SPSS. Jakarta: Elex Media Komputindo.

Susanto, A.B. (2006). Nama dan identitas merek, diambil dari http://jakartaconsulting.com/art-0116.html. 